\title{
Peronospora aquilegiicola made its way to Germany: the start of a new pandemic?
}

\author{
Marco Thines ${ }^{1,2,3}$ (D) Anthony Buaya ${ }^{1,2} \cdot$ Tahir Ali $^{1,2} \cdot$ Thomas Brand $^{4}$
}

Received: 5 June 2020 / Revised: 13 June 2020 / Accepted: 17 June 2020

(C) The Author(s) 2020

\begin{abstract}
Peronospora aquilegiicola is a destructive pathogen of columbines and has wiped out most Aquilegia cultivars in several private and public gardens throughout Britain. The pathogen, which is native to East Asia was noticed in England and Wales in 2013 and quickly spread through the country, probably by infested plants or seeds. To our knowledge, the pathogen has so far not been reported from other parts of Europe. Here, we report the emergence of the pathogen in the northwest of Germany, based on morphological and phylogenetic evidence. As the pathogen was found in a garden in which no new columbines had been planted recently, we assume that the pathogen has already spread from its original point of introduction in Germany. This calls for an increased attention to the further spread of the pathogen and the eradication of infection spots to avoid the spread to naturally occurring columbines in Germany and to prevent another downy mildew from becoming a global threat, like Peronospora belbahrii and Plasmopara destructor, the downy mildews of basil and balsamines, respectively.
\end{abstract}

Keywords Aquilegia $\cdot$ Downy mildew $\cdot$ Invasive species $\cdot$ Morphology $\cdot$ Quarantine $\cdot$ Phylogeny

\section{Introduction}

More than 700 oomycete species are known to cause downy mildew (Thines and Choi 2016). Oomycetes are fungal analogues of the kingdom Straminipila, which, despite their relationship with brown seaweeds and diatoms, have evolved a fungal habit, with an absorptive mode of nutrition and filamentous growth. The genus Peronospora is the largest genus of the oomycetes and contains several hundred species that are

Section Editor: Marc Stadler

Marco Thines

m.thines@thines-lab.eu

1 Department of Biological Sciences, Institute of Ecology and Evolution, Goethe University, Max-von-Laue-Str. 9, 60438 Frankfurt am Main, Germany

2 Senckenberg Biodiversity and Climate Research Centre, Georg-Voigt-Str. 14-16, 60325 Frankfurt am Main, Germany

3 Faculty of Agricultural Sciences, Institute of Phytopathology, University of Hohenheim, D-70593 Stuttgart, Germany

4 Chamber of Agriculture Lower Saxony, Plant Protection Service, Sedanstr. 4, 26121 Oldenburg, Germany obligate parasites of a variety of angiosperm hosts (Constantinescu 1991). A hallmark of the genus Peronospora is the high degree of host specificity, which is usually on the plant species level (e.g. Voglmayr 2003; García-Blázquez et al. 2008; Thines et al. 2009; Thines and Kummer 2013; Voglmayr et al. 2014; Choi et al. 2015a). Downy mildew caused by Peronospora is observed in many plant families, and especially Ranunculaceae, Amaranthaceae, Caryophyllaceae, Fabaceae, Plantaginaceae and Lamiaceae have many reported host genera and species (Constantinescu 1991).

Until the advent of molecular phylogenetics it was often assumed that species of downy mildews were mostly able to infect a whole family, but formae specialis, specialised forms, were frequently postulated (Yerkes and Shaw 1959). However, phylogenetic investigations have generally supported the narrow species concept advocated by Gäumann (1918, 1923) and others (Voglmayr 2003; Choi et al. 2015a), and revealed that in the genera Bremia and Peronospora genetic distinctiveness in accordance with the host species was present (Thines et al. 2011; Choi and Thines 2015). However, it was also found that not host codivergence but frequent host jumps, subsequent radiation and speciation drive the observed species-richness of the downy mildews (Choi and Thines 2015; Thines 2019). 
The observation of the high degree of host specificity in downy mildews has led to the reappraisal of the species diversity in many downy mildew species complexes, often focussed on economically important groups (Choi et al. 2009, 2015a, 2017, 2018; Thines et al. 2009, 2019; Thines 2011; Voglmayr et al. 2014; Görg et al. 2017). The genus Peronospora harbours various species of economic impact, of which P. belbahrii (Thines et al. 2009) and P. aquilegiicola (Thines et al. 2019) are pathogens that have just recently emerged. The downy mildew epidemic caused by $P$. belbahrii reached all major basil-producing areas of the world quickly. This was probably facilitated by the assumption that the pathogen was belonging to the widespread species, $P$. lamii, based on a broad species concept, which obstructed rapid installing of phytosanitary and quarantine measures to restrict the disease. At the time the pathogen was described a new species of Peronospora, it was already present globally (Thines et al. 2009). This was not the case for a pathogen of columbines (Aquilegia spp.) that recently emerged in Britain, wiping out most columbine plants in many public gardens throughout the island. In this case, already the first publication describing morphological and phylogenetic details highlighted that the species was an invasive pathogen, probably originating from East Asia (Denton et al. 2015; Thines et al. 2019). At the time of the formal description by Thines et al. (2019), the pathogen seemed to have been contained in Britain, probably because plant protection agencies had been made aware of the pathogen early.

However, very recently, downy mildew of columbines was observed in a private garden in Northwestern Germany, suggesting that the pathogen has made its way to continental Europe. It was the aim of this study to investigate the identity of this pathogen by detailed morphological and phylogenetic analysis to clarify, if $P$. aquilegiicola is now present in continental Europe, where it could be a potential threat to both cultivated and wild Aquilegia species.

\section{Material and methods}

\section{Plant material and microscopic investigation}

Aquilegia vulgaris plants with downy mildew symptoms were collected from a private garden in the outskirts of Oldenburg, Germany, in the first week of May 2020. According to the owners of the garden, first symptoms had been noticed in 2019, and in 2020 many plants throughout the garden were severely affected by fully systemic downy mildew infestation. After the collection, all columbines in the garden were removed and destroyed by incineration. Specimens were handled in a microbiology safety bench, dried between papers and deposited in the Herbarium Senckenbergianum (FR) under the accession number FR-0246022. For microscopic investigations, conidiophores were scraped from the lower surface of infected leaves into a drop of $70 \%$ aqueous lactic acid solution on a microscopic slide and covered with coverslips. Subsequently, they were investigated at $\times 400$ magnification in DIC using a Zeiss Imager 2 compound microscope equipped with an Axiocam colour camera (Zeiss, Oberkochen, Germany). Measurements were done from pictures using the Axiovision software (Zeiss, Oberkochen, Germany). Measurements are reported as (minimum-)mean minus standard deviation-mean-mean plus standard deviation(-maximum).

\section{DNA-preparation, PCR and sequencing}

For obtaining amplifiable DNA, small amounts of conidiophores and hyphae were scraped off the infected leaf surface. The material was homogenised in a $2 \mathrm{~mL}$ reaction tube containing two $3 \mathrm{~mm}$ stainless steel balls in a Retsch MM 400 mixer mill for $3 \mathrm{~min}$ at $25 \mathrm{~Hz}$. Subsequently, $500 \mu \mathrm{L}$ of a $5 \%$ suspension of Chelex 100 resin (Sigma-Aldrich Chemie $\mathrm{GmbH}$, Steinheim, Germany) were added to the tube. The mixture was heated to $95{ }^{\circ} \mathrm{C}$ for $10 \mathrm{~min}$ in a Thriller thermoshaker-incubater (PEQLAB Biotechnologie GMBH, Erlangen, Germany) with shaking at $700 \mathrm{rpm}$ for $10 \mathrm{~s}$ after every $2 \mathrm{~min}$. Subsequently, sporangiophores and resin were pelleted by centrifuging in a bench-top centrifuge (5702R, Eppendorf, Germany) at maximum speed for $1 \mathrm{~min}$ and the supernatant $(100 \mu \mathrm{L})$ was carefully removed, and transferred to a clean $1.5 \mathrm{~mL}$ Eppendorf tube. After this, $1 \mu \mathrm{L}$ of the supernatant was used for PCR reactions. PCR amplifications of the nuclear ribosomal internal transcribed spacers (ITS) and the mitochondrial cytochrome oxidase subunit II ( $\operatorname{cox} 2)$ were carried out as described by Choi et al. (2015b). PCR products were bidirectionally sequenced with the primers used for PCR at the laboratory centre of the Senckenberg Biodiversity and Climate Research Centre (SBiK-F). Obtained sequences were deposited in GenBank under the accession numbers MT554398 for ITS and MT547662 for cox2.

\section{Alignment and phylogenetic analysis}

GenBank (https://www.ncbi.nlm.nih.gov/Genbank/) was searched for similar sequences using blastn (Altschul et al. 1990). The aligned sequence stretches were downloaded, and from the results, sequences were removed to keep only two (in unclear cases up to five) sequences per species. Sequences were aligned on the TrEase webserver (https:// thines-lab.senckenberg.de/trease) using muscle (Edgar 2004) with standard settings. Leading and trailing gaps were cut, and subsequently, alignments were uploaded on the TrEase webserver (https://thines-lab.senckenberg.de/trease) for phylogenetic analyses. Minimum evolution inference was done using FastTree (Price et al. 2010) using the GTR 
substitution model and 1000 bootstrap replicates. Maximum likelihood inference was done using RAxML v8 (Stamatakis 2014) using the GTRGAMMA substitution model. Bayesian inference was done using MrBayes v3.2 (Ronquist et al. 2012) with six gamma categories and running for 5 Million generations, with every 10,000 th tree sampled and discarding the first $30 \%$ of the trees before calculating posterior probabilities, to ensure sampling from the stationary phase.

\section{Results}

\section{Morphology}

As viewed from above, infected columbine leaf tissue had a chlorotic appearance. Older lesions were attaining a reddish to purplish taint. The vein-delimited infections were sometimes not fully systemic, resulting in a polyangular pattern on the leaves. Only the outer part of the leaves was not affected in these cases, in line with the otherwise systemic infection of the plants. On the lower leaf surface a dense outgrowth of hyaline conidiophores bearing light brown conidia with a purplish hue was observed. Conidiophores protruded from the stomata on the underside of lesions, were erect and monopodially branched up to 6 orders, (141-)169-211-254(-287) $\mu \mathrm{m}$ long, (5-)5.6-6.8-8.0(-9) $\mu \mathrm{m}$ wide, sometimes swollen at the base; trunk (51-)64-78-92(-101) $\mu \mathrm{m}$, ratio total length to trunk length (2.4-)2.2-2.7-3.2(-3.9), $n=10$. Branching of the ultimate ramification was mostly rectangular. Ultimate branchlets were slightly curved, but substraight ultimate branchlets were also observed, tip obtuse or slightly pointed. The ultimate branchlets were mostly paired (95\%), with different lengths, $(5-) 7.3-9.8-12.3(-15.5) \mu \mathrm{m}$ for the longer ones $(n=100)$, (4-)5.9- $\underline{8}-10.1(-12.5) \mu \mathrm{m}$ for the shorter ones $(n=100)$, and a ratio of the longer to the shorter ultimate branchlet (1-)1.04-1.25-1.46(-2.15) $\mu \mathrm{m}$. Conidia were broadly ellipsoidal (13-)15.2-16.6-18.0(-20.5) $\mu \mathrm{m}$ long, (11-)12.2$13.2-14.2(-15.5)$ wide, with a length to width ratio of (1.04-)1.16-1.26-1.26(-1.44), $n=100$, directly germinating with a germ tube. An overview of the morphology is given in Fig. 1.

\section{Molecular phylogeny}

The sequences, for both ITS (Fig. 2) and cox2 (Fig. 3), were $100 \%$ identical to sequences from the type specimen of Peronospora aquilegiicola and clustered with $P$. aquilegiicola sequences derived from England and East Asia with maximum support. No additional sequences clustered at close distance. In the tree based on ITS sequences, $P$. aquilegiicola was embedded in a weakly supported group of species mostly from Ranunculales, which was the sister group of another weakly supported group mostly represented by species parasitic to Caryophyllales. In the cox2-based tree, a higher resolution on the species level was observed, but there was no supported grouping for most lineages above species level. However, most sequences found in the BLAST searches corresponded to species parasitic to Ranunculales and Caryophyllales, in line with the results from the ITS-based phylogeny.

\section{Discussion}

Unambiguous identification of species is a prerequisite for effective quarantine of pathogens and pests. However, in many plant pathogen groups, including downy mildews, this has been notoriously difficult, as many morphologically similar species exist, which complicates identification and calls for approaches combining various different methods (Spring and Thines 2004). In addition to these limitations, the knowledge regarding the diversity of plant parasitic oomycetes in general and downy mildews in particular is still fragmentary. This is mainly because there was the long-prevailing broad species concept in downy mildews, prominently advocated by Yerkes and Shaw (1959) for some downy mildew groups, which suggested that there is mostly just one downy mildew species per host family, informally subdivided into several more or less specialised forms. Thus, detailed morphological investigations were often not done when new hosts were recorded. As a consequence, downy mildew systematics, after a century of progress (e.g. de Bary 1863; Schröter 1886; Gäumann 1918, 1923; Gustavsson 1959) stalled for several decades. With the rise of molecular phylogenetics, the older, narrow species concept was appreciated again, as it was revealed that most downy mildews grouped together according to their host species (Riethmüller et al. 2002; Göker et al. 2003; Voglmayr 2003), leading to the reappraisal of various species.

In addition to these more general investigations, several studies focussed on downy mildew pathogens of various crops and ornamentals, especially those newly occurring, leading to the description of new species for the pathogens of arugula (Hyaloperonospora erucae, Choi et al. 2018), balsamines (Plasmopara destructor and Pl. velutina; Görg et al. 2017), basil (Peronospora belbahrii; Thines et al. 2009), boston ivy (Pl. muralis; Thines 2011), coleus (P. choii; Hoffmeister et al. 2020), maca (Perofascia macaicola; Choi et al. 2017), opium poppy (P. somniferi; Voglmayr et al. 2014) and sage (P. salviae-officinalis and $P$. salviae-plabeae; Choi et al. 2009).

Of these, especially P. belbahrii, $P$. somniferi and $P l$. destructor have become a global threat, as they are easily spread with infected plants or infested seeds (Thines and Choi 2016). However, while having a severe economic impact, they have no significant ecological effect, as in most 
Fig. 1 Macroscopic (A-D) and microscopic $(\mathbf{E}-\mathbf{H})$

characteristics of Peronospora aquilegiicola. a Systemically infected, slightly stunted host plant with malformed leaves; $\mathbf{b}$ chlorotic lesions on the upper leaf surface with beginning purplish discolouration; c lower surface of a nearly fully infected leaf with abundant sporulation with densely packed hyaline conidiophores bearing and light brown conidia with a purplish hue; $\mathbf{d}$ close-up of the bearing lower leaf surface of a nearly fully infected leaf; e conidiophore; $\mathbf{f}$ branches; $\mathbf{g}$ ultimate branchlets; and $\mathbf{h}$ conidia. $\mathbf{B a r}=50 \mu \mathrm{m}$ in $\mathbf{e}$ and $20 \mu \mathrm{m}$ in $\mathbf{f}-\mathbf{h}$

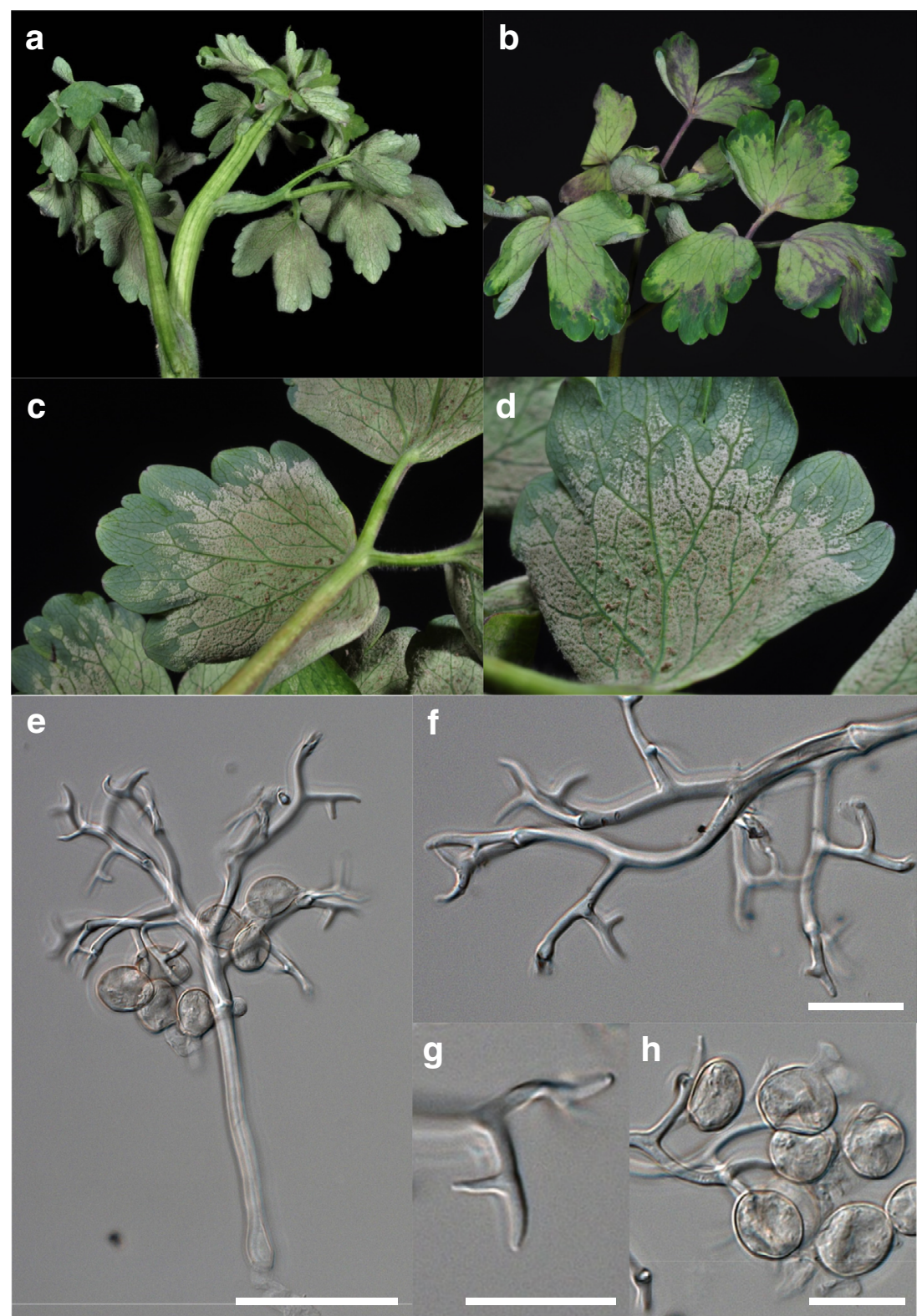

countries into which they were introduced, no native hosts were present. This situation is different with $P$. aquilegiicola (Denton et al. 2015; Thines et al. 2019), which has recently been introduced to Britain, most likely from East Asia (Denton et al. 2015). Throughout Europe, Aquilegia species occur naturally, and many are not widely distributed. Thus, in addition to the economic harm of $P$. aquilegiicola in the production of columbines, the species also poses an ecological threat to wild Aquilegia species, especially those that occur only locally. Therefore, it is of great importance to eradicate the species in Britain and to prevent the spread throughout Europe. In contrast to $P$. belbahrii and $P l$. destructor, $P$. aquilegiicola was recognised and described as a new species before the onset of a global pandemic, and luckily, the species could so far be contained in Britain.
However, the confirmation of the pathogen in the northwest of Germany in this study shows that $P$. aquilegiicola has made its way into continental Europe. At the spot where the pathogen was now observed, pathogen eradication measures are taken and an express pest risk analysis for the species was compiled (Wilstermann 2020). In the garden where the disease was

Fig. 2 Phylogenetic reconstruction (Minimum Evolution) based on internal transcribed spacer (ITS) sequences. Numbers on branches denote bootstrap support values for minimum evolution and maximum likelihood analyses, as well as posterior probabilities from Bayesian Inference, in the respective order. Only support values $>65 \%$ (bootstrap support) or 0.85 (posterior probability) are displayed. A dash denotes lack of support for the presented or an alternate topology in the respective analysis 


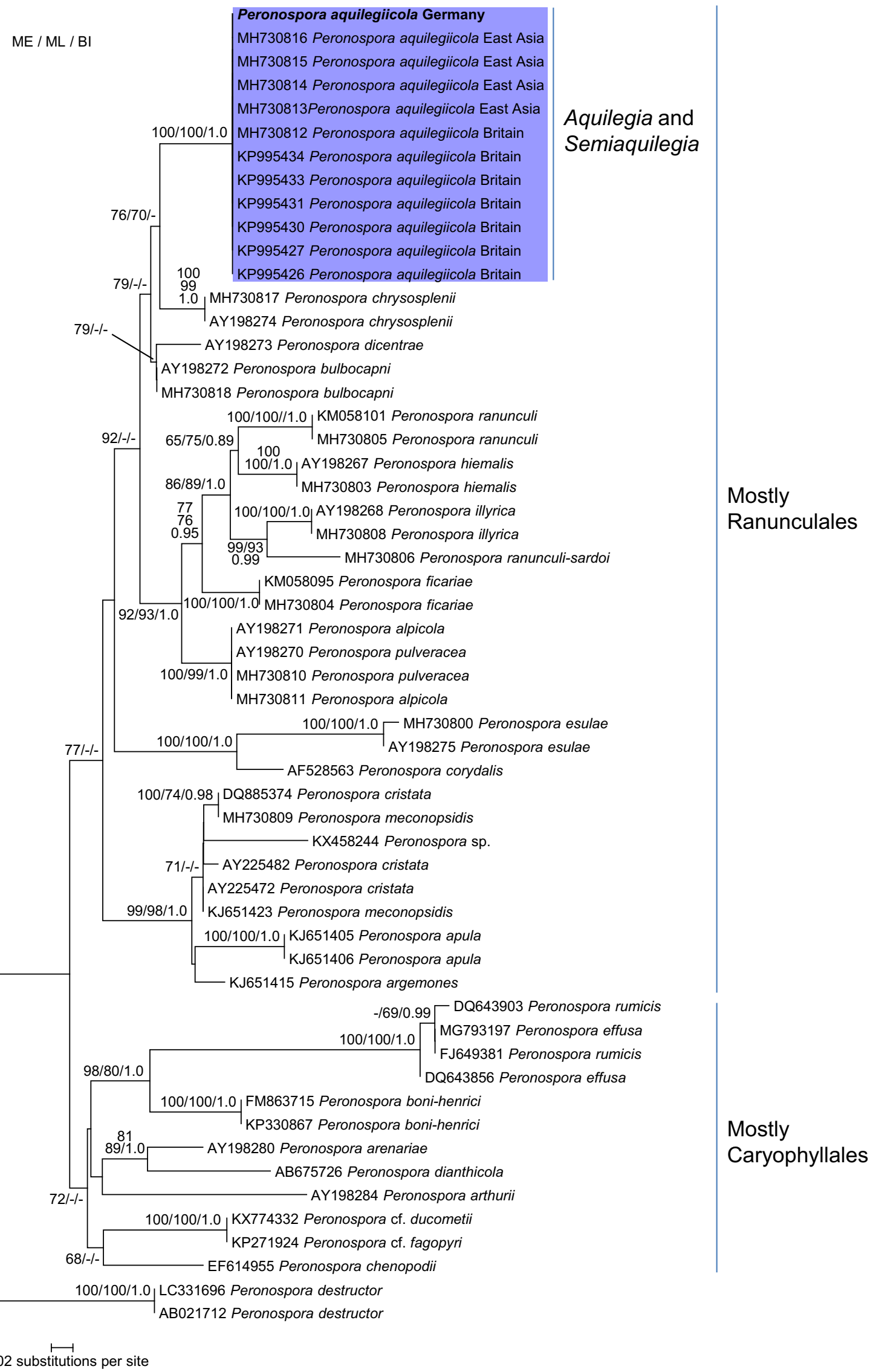


$\mathrm{ME} / \mathrm{ML} / \mathrm{BI}$

Peronospora aquilegiicola Germany

MH730778 Peronospora aquilegiicola East Asia

MH730777 Peronospora aquilegiicola East Asia

$100 / 100 / 1.0$

MH730776 Peronospora aquilegiicola East Asia

MH730775 Peronospora aquilegiicola East Asia

MH730774 Peronospora aquilegiicola Britain

DQ365729 Peronospora sanguisorbae
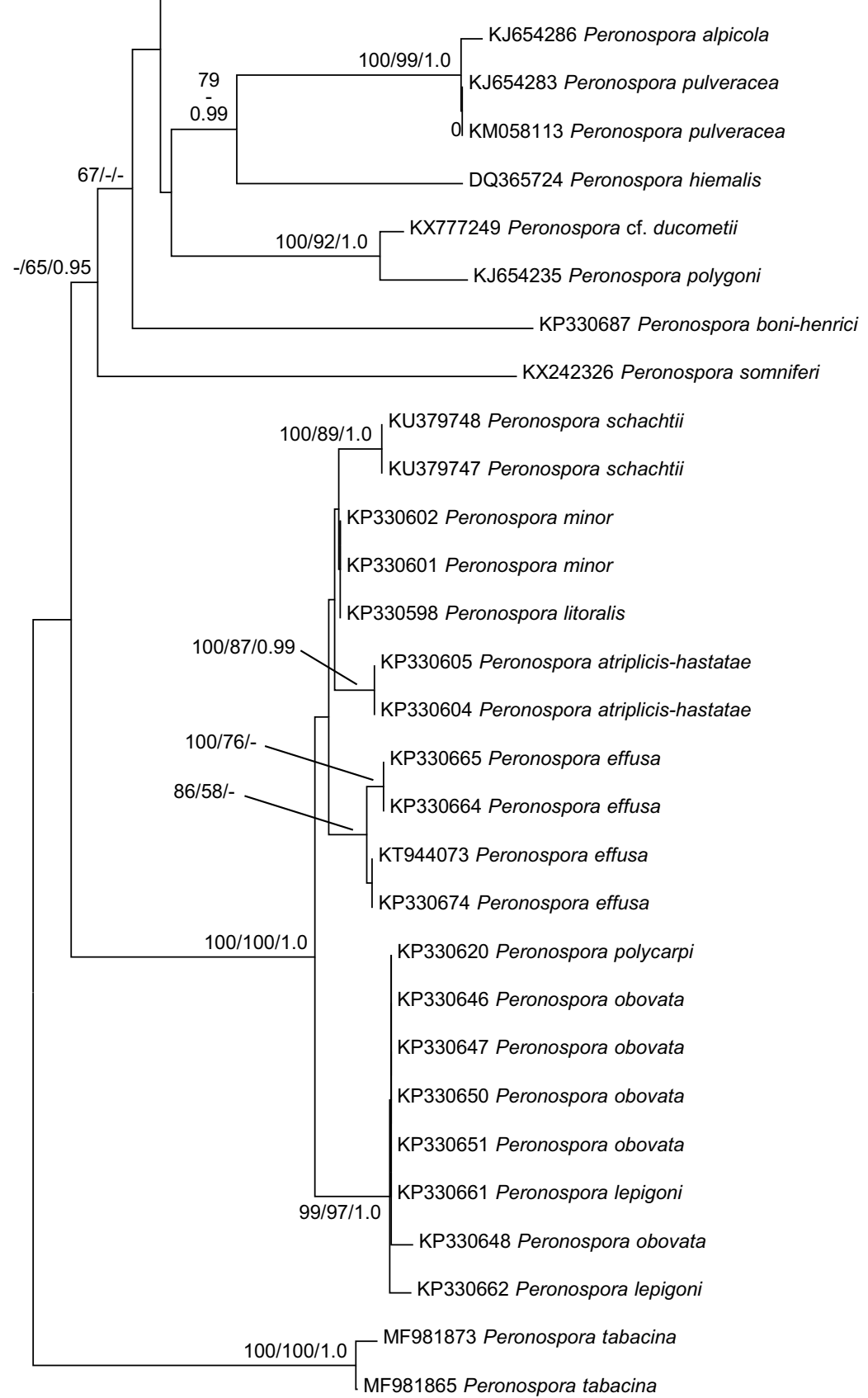

$\longmapsto$

0.005 substitutions per site
Aquilegia and Semiaquilegia 
Fig. 3 Phylogenetic reconstruction (minimum evolution) based on cytochrome oxidase subunit 2 ( $\operatorname{cox} 2$ ) sequences. Numbers on branches denote bootstrap support values for minimum evolution and maximum likelihood analyses, as well as posterior probabilities from a Bayesian Inference, in the respective order. Only support values $>65 \%$ (bootstrap support) or 0.85 (posterior probability) are displayed. A dash denotes lack of support for the presented or an alternate topology in the respective analysis

recognised by the owners first in 2019 (reported by them in May 2020), columbines were not planted or sown in the last 20 years; there was neither purchase nor import of plants or seeds of this genus. The population probably originates from the neighbourhood and is maintained by self-seeding. This suggests that the pathogen was recently introduced by air-borne conidia from adjacent gardens; however, the occurrence of the disease in the vicinity of the garden is not known yet. The local plant protection authority will monitor the situation closely with the aim to identify the original inoculum source and to eradicate the pathogen from the area. Even though it is known that conidia of Peronospora can travel large distances (Aylor et al. 1982), given the localised presence in a private garden, it seems more likely that the pathogen was introduced to the area with infested plants or seeds than that is was transported from Btritain by wind.

The confirmation of $P$. aquilegiicola in Germany underlines the dispersion potential of the pathogen and calls for increased alertness in European countries and beyond, in order to avoid another downy mildew pandemic, this time with the potential of a severe ecological impact. Therefore, information on the occurrence of the pathogen should be spread to all stakeholders, for example, in the EPPO Global Database (EPPO 2020) as well as consumer magazines. The economic, environmental and social impact of the pathogen should be critically assessed and the pathogen classified accordingly. Furthermore, appropriate phytosanitary measures should be consequently implemented in order to successfully eradicate the disease before it becomes widespread.

Acknowledgements Sebastian Ploch is gratefully acknowledged for laboratory support.

Author contribution MT conceived the study, TB provided pathogen material and photos of diseased plants, ATB and TA processed specimens, MT performed measurements and analysed the morphological data, MT edited sequences and performed phylogenetic analyses, MT produced all figures and MT wrote the manuscript, with contributions from the other authors.

Funding Information Open Access funding provided by Projekt DEAL.

Open Access This article is licensed under a Creative Commons Attribution 4.0 International License, which permits use, sharing, adaptation, distribution and reproduction in any medium or format, as long as you give appropriate credit to the original author(s) and the source, provide a link to the Creative Commons licence, and indicate if changes were made. The images or other third party material in this article are included in the article's Creative Commons licence, unless indicated otherwise in a credit line to the material. If material is not included in the article's Creative Commons licence and your intended use is not permitted by statutory regulation or exceeds the permitted use, you will need to obtain permission directly from the copyright holder. To view a copy of this licence, visit http://creativecommons.org/licenses/by/4.0/.

\section{References}

Altschul SF, Gish W, Miller W, Myers EW, Lipman DJ (1990) Basic local alignment search tool. J Mol Biol 215:403-410

Aylor DE, Taylor GS, Raynor GS (1982) Long-range transport of tobacco blue mold spores. Agric Meteorol 27:217-232

Choi Y-J, Thines M (2015) Host jumps and radiation, not co-divergence drives diversification of obligate pathogens. A case study in downy mildews and Asteraceae. PLoS One 10:e133655

Choi Y-J, Shin H-D, Thines M (2009) Two novel Peronospora species are associated with recent reports of downy mildew on sages. Mycol Res 113:1340-1350

Choi Y-J, Klosterman SJ, Kummer V, Voglmayr H, Shin HD, Thines M (2015a) Multi-locus tree and species tree approaches toward resolving a complex clade of downy mildews (Straminipila, Oomycota), including pathogens of beet and spinach. Mol Phylogenet Evol 86: 24-34

Choi Y-J, Beakes G, Glockling S, Kruse J, Nam B, Nigrelli L, Ploch S, Shin H-D, Shivas G, Telle S, Voglmayr H, Thines M (2015b) Towards a universal barcode of oomycetes - a comparison of the cox 1 and cox 2 loci. Mol Ecol Resour 15:1275-1288

Choi Y-J, Thines M, Choi I-Y, Shin H-D (2017) Perofascia is not monotypic: the description of the second taxon affecting the South American crop maca (Lepidium meyenii). Mycol Prog 16:857-864

Choi Y-J, Kruse J, Thines M (2018) Hyaloperonospora erucae sp. nov. (Peronosporaceae; Oomycota), the downy mildew pathogen of arugula (Eruca sativa). Eur J Plant Pathol 151(2):549-555

Constantinescu O (1991) An annotated list of Peronospora names. Thunbergia 15:1-110

de Bary A (1863) Recherches sur le développement de quelques champignons parasites. Ann Sci Natur Botanique Sér 20:5-148

Denton GJ, Beal EJ, Kilty A, Denton JO, Choi Y-J, Thines M (2015) Characterisation and risk assessment of the emerging Peronospora disease on Aquilegia. Mycol Prog 14(69):1-10

Edgar RC (2004) MUSCLE: multiple sequence alignment with high accuracy and high throughput. Nucleic Acid Res 32:1792-1797

EPPO (2020) EPPO Global Database. https://gd.eppo.int/

García-Blázquez G, Göker M, Voglmayr H, Martín MP, Tellería MT, Oberwinkler F (2008) Phylogeny of Peronospora, parasitic on Fabaceae, based on ITS sequences. Mycol Res 112:502-512

Gäumann E (1918) Über die Formen der Peronospora parasitica (Pers.) Fries. Ein Beitrag zur Speziesfrage bei den parasitischen Pilzen. Beihefte zum Botanischen Centralblatt 35:395-533

Gäumann EA (1923) Beiträge zu einer Monographie der Gattung Peronospora Corda. Beiträge zur Kryptogamenflora der Schweiz 5:1-360

Göker M, Voglmayr H, Riethmüller A, Weiß M, Oberwinkler F (2003) Taxonomic aspects of Peronosporaceae inferred from Bayesian molecular phylogenetics. Can J Bot 81:672-683

Görg M, Ploch S, Kruse J, Kummer V, Runge F, Choi Y-J, Thines M (2017) Revision of Plasmopara (Oomycota, Peronosporales) parasitic to Impatiens. Mycol Prog 16:791-799

Gustavsson A (1959) Studies on nordic peronosporas. I. Taxonomic revision. Opera Bot 3:1-271 
Hoffmeister M, Ashrafi S, Thines M, Maier W (2020) Two new species of the Peronospora belbahrii species complex, Pe. choii sp. nov. and $P$ e. salviae-pratensis sp. nov., and a new host for Pe. salviaeofficinalis. FUSE 6:39-59

Price MN, Dehal PS, Arkin AP (2010) FastTree2-approximately maximum-likelihood trees for large alignments. PLoS One 5:e9490

Riethmüller A, Voglmayr H, Göker M, Weiß M, Oberwinkler F (2002) Phylogenetic relationships of the downy mildews (Peronosporales) and related groups based on nuclear large subunit ribosomal DNA sequences. Mycologia 94:834-849

Ronquist F, Teslenko M, van der Mark P, Ayres DL, Darling A, Hohna S, Larget B, Liu L, Suchard MA, Huelsenbeck JP (2012) MrBayes 3.2: efficient Bayesian phylogenetic inference and model choice across a large model space. Syst Biol 61:539-542

Schröter J (1886) Fam. Peronosporacei. In: Cohn F (ed) KryptogamenFlora von Schlesien. J.U.Kern, Breslau

Spring O, Thines M (2004) On the necessity of new characters for classification and systematics of obligate biotrophic Peronosporomycetes. Planta 219:910-914

Stamatakis A (2014) RAxML version 8: a tool for phylogenetic analysis and post-analysis of large phylogenies. Bioinformatics 30:13121313

Thines M (2011) Recent outbreaks of downy mildew on grape ivy (Parthenocissus tricuspidata Vitaceae) in Germany are caused by a new species of Plasmopara. Mycol Prog 10:415-422

Thines M (2019) An evolutionary framework for host shifts-jumping ships for survival. New Phytol 224:605-617

Thines M, Choi Y-J (2016) Evolution, diversity, and taxonomy of the Peronosporaceae, with focus on the genus Peronospora. Phytopathology 106:6-18
Thines M, Kummer V (2013) Diversity and species boundaries in floricolous downy mildews. Mycol Prog 12:321-329

Thines M, Telle S, Ploch S, Runge F (2009) Identity of the downy mildew pathogens of basil, coleus, and sage with implications for quarantine measures. Mycol Res 113:532-540

Thines M, Runge F, Telle S, Voglmayr H (2011) Phylogenetic investigations in the downy mildew genus Bremia reveal several distinct lineages and a species with a presumably exceptional wide host range. Europ J Pl Pathol 129:81-89

Thines M, Denton GJ, Beal EJ, Kilty A, Denton JO, Shin H-D et al (2019) Peronospora aquilegiicola sp. nov., the downy mildew affecting columbines in the UK is an invasive species from East Asia. Europ J P1 Pathol 155:515-525

Voglmayr H (2003) Phylogenetic relationships of Peronospora and related genera based on nuclear ribosomal ITS sequences. Mycol Res 107:1132-1142

Voglmayr H, Montes-Borrego M, Landa BB (2014) Disentangling Peronospora on Papaver: phylogenetics, taxonomy, nomenclature and host range of downy mildew of opium poppy (Papaver somniferum) and related species. PLoS One 9:e96838

Wilstermann A (2020) Express-PRA zu Peronospora aquilegiicola. https://pflanzengesundheit.julius-kuehn.de/dokumente/upload/ Peronospora-aquilegiicola_Exp-PRA.pdf

Yerkes WD, Shaw CG (1959) Taxonomy of the Peronospora species on Cruciferae and Chenopodiaceae. Phytopathology 49:499-507

Publisher's note Springer Nature remains neutral with regard to jurisdictional claims in published maps and institutional affiliations. 